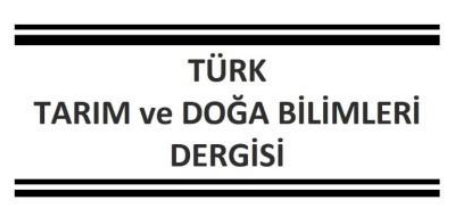

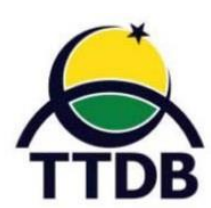

www.dergipark.gov.tr/turkjans

Araştırma Makalesi

\title{
Farklı Sulama Suyu Tuzluluk Düzeylerinin Mısırın Fide Gelişimine Etkileri
}

\author{
Yalçın COŞKUN ${ }^{1 *}$, İsmail TAŞ ${ }^{2}$, Mevlüt AKÇURA ${ }^{3}$, Ayhan ORAL ${ }^{4}$, Tülay TÜTENOCAKLI ${ }^{1}$, Tuğba YETER ${ }^{5}$ \\ ${ }^{1}$ Çanakkale Onsekiz Mart Üniversitesi, Lapseki Meslek Yüksek Okulu, Tıbbi ve Aromatik Bitkiler Programı \\ ${ }^{2}$ Çanakkale Onsekiz Mart Üniversitesi, Ziraat Fakültesi, Tarımsal Yapılar ve Sulama Bölümü \\ ${ }^{3}$ Çanakkale Onsekiz Mart Üniversitesi, Ziraat Fakültesi, Tarla Bitkileri Bölümü \\ ${ }^{4}$ Çanakkale Onsekiz Mart Üniversitesi, Fen Edebiyat Fakültesi, Kimya Bölümü \\ ${ }^{5}$ Toprak Gübre ve Su Kaynakları Merkez Araştırma Enstitüsü \\ *sorumlu yazar: ycoskun33@hotmail.com
}

\section{Geliş Tarihi: 28.04.2020 Düzeltme Geliş Tarihi: 10.09.2020 Kabul Tarihi: 15.10.2020}

\section{$\overline{O ̈ z}$}

Sulama suyunun SAR değeri suyun kalite sınıfının belirlenmesinde birincil parametredir. Bu nedenle SAR değeri dikkate alınmadan sodyum tuzu ile yapılan çalışmalarda elde edilen sonuçlar tuz zararı olmayıp sodyum zararını temsil etmektedir. Mısır bitkisinin sulama suyu tuzluluğunu hangi seviyeye kadar tolere edilebileceğini tespit etmek amacıyla SAR değeri 1'in altında ayarlanarak farklı tuz konsantrasyonuna sahip sulama suları ile çimlendirme ve saksı denemeleri yapılmıştır. Çimlendirme denemesi sonucunda sulama suyu tuzluluk seviyesindeki artışa paralel olarak kök uzunluğu, fide kuru ağırlığı ve çimlenme oranı azalmıştır. Kök uzunluğu sulama suyu tuzluluğunun $3 \mathrm{dS} \mathrm{m}^{-1} \mathrm{ECi}$ seviyesinde olumsuz etkilenmeye başlarken fide kuru ağırlığı ve çimlenme oranı $5 \mathrm{dS} \mathrm{m}^{-1} \mathrm{ECi}$ seviyesinde etkilenmeye başlamışır. Saksı denemesinde sulama suyu tuzluluk seviyesindeki artışa paralel olarak bitki boyu ve bitki kuru ağırlığı değerleri azalmış olup $8 \mathrm{dS} \mathrm{m}^{-1} \mathrm{ECi}$ seviyesinde olumsuz etkilenmiştir.

Anahtar kelimler: Mısır, sulama suyu tuzluluğu, çimlenme, SAR

\section{The Effects of Different Irrigation Water Salinity Levels on Seedling Development of Maize}

\section{Abstract}

The SAR value of irrigation water is the primary parameter in determining the quality class of the water. For this reason, the results obtained in studies with sodium salt without taking into account the SAR value are not salt losses and represent sodium losses. In order to determine to what level the maize plant's irrigation water salinity can be tolerated, germination and pot experiments were carried out using irrigation waters with different salt concentrations so that the SAR value is less than 1. As a result of germination trial, parallel to the increase in irrigation water salinity, root length, seedling dry weight, and germination rate decreased. The root length started to be affected negatively at $3 \mathrm{dS} \mathrm{m}^{-1} \mathrm{ECi}$ level of irrigation water salinity, seedling dry weight and germination rate started to be affected at $5 \mathrm{dS} \mathrm{m}^{-1} \mathrm{ECi}$ level. In the pot experiment, parallel to the increase in irrigation water salinity, plant height and plant dry weight values decreased and were negatively affected at $8 \mathrm{dS} \mathrm{m}^{-1} \mathrm{ECi}$ level.

Keywords: Maize, irrigation water salinity, germination, SAR 


\section{Giriş}

Mısır buğday ve çeltik ile birlikte dünyada en
çok ekilen ve tüketilen ürün grubunu oluşturmaktadır. Sıcak iklim tahılı olması nedeniyle daha çok ılıman iklim kuşağında yetiştirilmektedir. Hem insan gıdası ve hayvan yemi olarak oldukça büyük öneme sahip olan mısır aynı zamanda biyoetanol ve glikoz şurubu için önemli bir sanayi hammaddesidir. Danesi işlendikten sonra geriye kalan embriyosundan mısır özü yağı elde edilmektedir. Bu denli yaygın kullanıma sahip olduğu içinde mısır ile ilgili bilimsel çalışmalar oldukça popülerdir. Son yıllarda mısır ile ilgili yapılan biyotik ve abiyotik stres faktörlerine yönelik çalışmalar artma eğilimindedir. Bu çalışmalarda da toprak ve sulama suyu tuzluluğu dikkat çekmektedir. Düşük kalite sulama suları ile bitki yetiştirilen alanlarda hem bitkiler hem de topraklar olumsuz etkilenmektedir. Tuzdan etkilenen toprak, sorunlu topraktır. Yaşamın vazgeçilmez unsuru olan su, son yıllarda yaşanan kuraklık ve tüm sektörlerde su talebinin hızlı artışı sonucu daha önemli hale gelmiş olup, su kaynaklarının akılcı kullanımı ve korunması, ulusal ve uluslararası düzeyde önemini arttırmaktadır. Nüfus artışındaki hızla birlikte artan gıda ihtiyacı, tarımsal su ihtiyacının artmasına neden olmaktadır. Su kullanımı konusunda, farklı sektörler arasında artan rekabet, suyun daha çok kullanıldığı tarım alanında suyun tasarruflu kullanımını zorunluluk hale getirmektedir. Son yıllarda yaşanan iklim düzensizlikleri öncelikli olarak toprak ve su kaynakları ile tüm doğal kaynakların daha randımanlı ve etkin kullanımını zorunlu kılmıştır. Bu çerçevede düşük kalite sulama sularının tarımsal üretimde kullanımının sağlanması büyük önem arz etmektedir.

Tuzluluğun bitkiler üzerinde, su ve bitki besin maddelerinin alımına ilişkin ozmotik etkisinin yanında doğrudan zehirleyici etkisi de mevcuttur (Lewitt, 1980). Su ve besin maddesi alınımına etkisi tuzluluğun bitkiler üzerindeki ikincil etkisi olarak kabul edilirken zehirleyici etki birinci tuz zararı sayılmaktadır. Tuzluluk, ozmotik denge ve iyon dengesi ve ayrıca, hormonal dengesizliğe yol açarak, bitkilerin büyüme ve gelişmesini olumsuz etkilemektedir (Ashraf ve Foolad, 2007). Tuzlu topraklarda ozmotik potansiyelin artması nedeniyle bitkiler, ihtiyaç duyduğu suyu yeterince kullanamaz veya ortamda fazlaca mevcut hale gelen $\mathrm{Na}$ ve $\mathrm{Cl}$ iyonlarından kaynaklanan zehirleyici etki nedeniyle bitkiler tarafından su alımı azalmaktadır. Bitkilerin bünyesine aldığı fazla tuzun, hücrelerin faaliyetlerini bozması, hücrelere ve organellere zarar vermesi ve bu vesile ile fotosentez, solunum gibi fizyolojik aktivitelerin normal seyrinin bozulmasına neden olması tuz zararının sonuçlarındandır (Kalefetoğlu ve Ekmekçi, 2005). Mısırın çimlenme ve stant oluşumu tuz stresine daha sonraki gelişim aşamalarından daha duyarlıdır. Toprağın yüksek sodyum ve klorür içeriği bitkinin azot, potasyum, kalsiyum, alınımını olumsuz yönde etkiler. Kanber ve Ünlü (2010) topraktaki tuz yoğunluğunun artışı ile bitkilerin topraktan su alımının zorlaştığını, toprağın yapısındaki bozulmalar neticesinde bitkilerin gelişimlerinin gerilediğini belirtmişlerdir. Kültür bitkilerinin yetiştirildiği ortamda tuzluluk seviyesi artışıyla birlikte ürünün verimi bitkilerin tuza tolerans seviyesine paralel azalabilir. Mesela, tuza dayanımı yüksek olan buğday bitkisinde tane veriminin azalışa geçtiği sulama suyu tuzluluk eşik değeri $6 \mathrm{dS} \quad \mathrm{m}^{-1}$ ve $\% 50$ verim kaybı ile sonuçlanacağı, toprak tuzluluğu için ise bu değerin

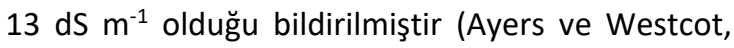
1994; Kanber ve Ünlü, 2010). Tuz stresi, bitkilerin ölümüne neden olabilmekte, tuz konsantrasyonu ve bitkinin toleransına bağlı olarak büyümesini engelleyebilmekte, yapraklarda yanıklık benzeri hasarlara, klorozlara, döllenmede bozukluklara, meyvelerin normalden küçük olmasına, verim ve kalitesinin azalmasına sebep olabilmektedir (Özcan ve ark., 2001). Toprakta biriken tuz bitkilerin büyüme ve gelişmesini farklı oranlarda etkileyebileceği gibi bitki türlerine göre tepkiler de farklı olabilmektedir (Kara ve ark. 2011). Kurak ve yarı kurak bölgelerde çimlenmede yeknesaklığa olumsuz yönde etkiye sahip başlıca önemli çevresel etkenlerden bir tanesi tuzluluktur (Demir ve ark., 2003). Tuzluluk çalışmalarında bitki türlerinin tuza tepkilerinin belirlenmesinde çimlenme ve fide gelişim dönemleri daha çok dikkate alınmaktadır (Van Hoorn ve ark., 2001). Yüksek tuz yoğunluğunda çimlenmede görülen olumsuz etkilerin asıl sebebi tohumun su alımının sekteye uğramasıdır (Mansour, 1994). Tuzluluk problemine sahip topraklardaki yetiştirilen bitkilerin verim kaybının sebepleri; içerisinde fazlaca bulunan Na ve $\mathrm{Cl}$ iyonlarının oluşturduğu zehirleyici etki, bitkideki iyonsal denge bozuklukları (Flowers ve Yeo, 1981), bitkinin besin maddesi alması ile taşımasındaki olumsuzluklar, özümleme ile solunum gibi hayati önemdeki fizyolojik aktivitelerinin zarara uğraması (Leopold ve Willing, 1984) sayılmaktadır. Bunların dışında tuzluluk problemli olan topraklarda bitkilerde fazlaca birikebilen $\mathrm{Na}$ iyonu, potasyumun alınmasına (Siegel ve ark., 1980), Cl iyonu da NO3 alınımına ket vurarak (Inal ve ark., 1995) bitkilerin iyonsal denge bozukluklarına maruz kalmasına sebebiyet verebilmektedir.

Dünyada olduğu gibi ülkemizde de üretimi ve tüketimi en yaygın olan tahıl cinslerinden birisi mısırdır. Dolayısıyla tüm dünyada mısırın verim, kalite ve üretiminde kullanılan kaynakların 
elverişliliğini artırma üzerine çalışmalar her zaman güncelliğini korumaktadır. Mısır bitkisinde tuzluluğun etkileri üzerine bu güne kadar yapılan çalışmalarda daha çok sodyum tuzu kullanılmış ve SAR değeri dikkate alınmamıştır. Bilindiği gibi sulama suyunun SAR değeri suyun kalite sınıfının belirlenmesinde birincil parametredir. Çalışmanın amacl; mısır yetiştiriciliğinde kullanılan sulama sularının hangi ECi seviyesine (SAR değeri 1'den küçük olacak şekilde) kadar bitki tarafından tolere edilebileceğini tespit etmektir.

\section{Materyal ve Metot \\ Çimlendirme Denemesi}

Laboratuvarda bulunan tezgahların üzeri Hidroklorik asit çözeltisi (\%2'lik) ile sterilize edildikten sonra ISI yalıtımı için polietilen ile kaplanmıştır. Denemede kullanılacak mısır tohumları (72MAY99 at dişi mısır çeşidi) mikrobiyal bulaşmalardan arındırmak için hidroklorik asit çözeltisinde (\%2'lik) 10 dakika bekletilerek sonrasında 3 kez steril saf su ile yıkanmıştır. Çimlendirme çalışmaları için sulama suyu olarak kullanılacak suyun SAR değeri 1'den küçük olacak şekilde farklı tuzluluk kaynakları $\left(\mathrm{NaCl}, \mathrm{MgSO}_{4}\right.$, $\mathrm{CaCl}_{2}$ ) kullanılarak tuzluluk seviyeleri (kontrol, 1, 2, $3,4,5,6,7,8,9,10,12,16$ ve $20 \mathrm{dS} \mathrm{m}^{-1}$ ) oluşturulmuştur. Laboratuvar koşullarında "tesadüf parselleri" deneme desenine göre 4 tekrarlamalı olarak yürütülen denemede her konu için 10 tohum, içerisine Whatman No.1 fitre kâğıdı yerleştirilen Petri kaplarına (15 cm çapında) konulmuştur. Petri kapları içerisine $20 \mathrm{ml}$ farklı dozlarda tuz ihtiva eden çözelti konularak buharlaşmayı önlemek için parafin film ile kaplanmıştır. Farklı tuz yoğunluklarının mısır tohumlarının çimlenmesine etkilerini tespit etmek amacıyla tohumlar Petri kapları içerisinde 7 gün süresince laboratuvar şartlarında tutularak her gün çimlenen tohum sayıları kaydedilmiştir. Gözlemler her gün aynı saatte yapılarak en az 1'er mm uzunluğunda 1 adet sapçık ile 1 adet kökçük çıkartan tohumlar çimlenmiş tohum olarak kaydedilmiştir. Her bir Petri içerisinde çimlenmiş olan tohumların sayısı toplam ekilen tohum sayısına oranlanarak yüzde çimlenme oranları tespit edilmiştir.

\section{Saksı Denemesi}

Çalışmada 6400 g kuru harç toprağı kapasitesine sahip saksılar kullanılmıştır. Deneme kumlu bünyeye (Kum: \%68, Silt: \%13.1, Kil:\%18.8, Hacim ağırlığı: $1.58 \mathrm{gr} \mathrm{cm}^{-3}$ ) sahip bir toprakta yürütülmüştür. Denemenin yürütüldüğü harç, tarla toprağı/kum/yanmış ahır gübresi (1/1/1) karışımından hazırlanmıştır. Saksılar serbest drenaj olacak şekilde yerleştirilmiştir. Saksılara taban

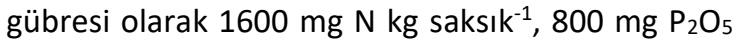
$\mathrm{kg} \mathrm{saksI}^{-1}$ ve $1000 \mathrm{mg} \mathrm{K} \mathrm{O} \mathrm{kg} \mathrm{saks}^{-1}$ seviyesinde gübre uygulaması yapılmıştır. Harç toprağı gübrelerle iyice karıştırılarak saksılara doldurulmuştur. Hazırlanan harç toprağından $2 \mathrm{~kg}$ başlangıç toprak örneği olarak ayrılmış ve analizler için muhafaza altına edilmiştir. İstenilen oranlarda tuzluluk seviyesi 150 litre hacmindeki su depolarının içerisinde $\mathrm{NaCl}, \mathrm{Mg} \mathrm{SO} \mathrm{S}_{4}$ ve $\mathrm{CaCl}_{2}$ tuzlarından yararlanılarak farklı tuzluluk seviyelerine sahip sulama suları oluşturulmuştur. Hazırlanan bu sular sulama suyu olarak denemede kullanılmıştır. Toprak analizlerinde çimlendirme denemesi sonuçlarına göre belirlenen kontrol, 1, 3, $5,8,12$ ve $16 \mathrm{dS} \mathrm{m}^{-1}$ tuz seviyeleri dikkate alınmıştır. Saksı denemeleri "tesadüf blokları" deneme desenine göre 3 tekrarlamalı olarak yürütülmüştür. Saksılara 4'er adet tohum ekilmiş olup fide çıkışları gerçekleştikten sonra saksı başına 2'şer adet fide kalacak şekilde seyreltme gerçekleştirilmiştir. Tohumların ekimi yapıldıktan sonra toprak, farklı tuzluluk seviyelerindeki sulama suları ile sulanmaya başlamıştır. Konulara uygulanacak sulama sularının ECi değeri olası her hangi bir değişikliğe karşı her sulama öncesi kontrol edilmektedir. Kontrol uygulaması çeşme suyu (ECi

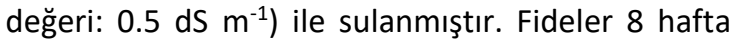
süresince gelişmeye bırakılmış ve süre sonunda ölçümler ile incelemeler yapılmıştır. Her saksıda bulunan bitkilerden veriler ayrı ayrı ölçülerek ortalamaları alınmış ve her saksı bir tekerrür olarak kabul edilmiştir. Bağcl ve ark., (2003)'ün bildirdiği gibi; çimlenme oranı, kök uzunluğu, fide kuru ağırlığı, bitki boyu ve bitki kuru ağırlığı belirlenmiştir.

\section{Tuzluluk Analizleri} alınmıştır.

Çalışmada her saksıdan toprak örneği Hava kuru olan topraklar $2 \mathrm{~mm}$ elekten elenerek 100 g tartılıp plastik veya porselen bir kaba konmuştur. Bir büret ya da ölçü silindiri ile yavaş bir şekilde saf su ilave edilerek bir spatül yardımı ile karıştırılmış ve çamur haline gelmesi sağlanmıştır. Çamurdan elde edilen ekstraksiyon sularında tuzluluk analizleri (EC, $\mathrm{pH}, \mathrm{Ca}, \mathrm{Mg}, \mathrm{Na}, \mathrm{K}, \mathrm{CO}_{3}$, $\mathrm{HCO}_{3}, \mathrm{Cl}$ ve $\mathrm{SO}_{4}$ ) yapılımıştır.

Çimlendirme ve saksı denemelerine ait verilere JMP 13 istatistik paket programı yardımıyla varyans analizleri ve student's $t$ çoklu karşılaştırma testi uygulanmıştır. 


\section{Bulgular ve Tartışma \\ Çimlendirme Denemesi}

Yapılan varyans analizleri sonucunda incelenen tüm özellikler açısından sulama suyu tuzluluk seviyelerinin etkileri istatistiki anlamada önemli bulunmuş olup $(P<0.01)$ ortalamalar student's t testi ile karşılaştırılmıştır.

Sulama suyu tuzluluk seviyesindeki artışa paralel olarak kök uzunluğu değerleri azalmış olup $3 \mathrm{dS} \mathrm{m}^{-1}$ ECi seviyesinde $11.781 \mathrm{~cm}$ değeriyle kontrolden
$(13.062 \mathrm{~cm})$ farklı bir grup ortaya çıkmıştır. Sulama suyu tuzluluk seviyesindeki artışa paralel olarak

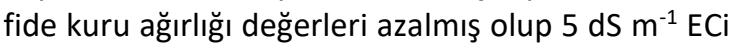
değerinde $(0.15418 \mathrm{~g})$ kontrolden $(0.19357 \mathrm{~g})$ farklı bir grup ortaya çıkmıştır. Sulama suyu tuzluluk seviyesindeki artışa paralel olarak çimlenme oranı

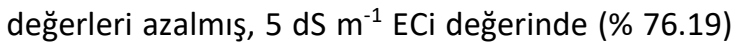
kontrolden (\%100) farklı bir grup ortaya çıkmıştır (Çizelge 1).

Çizelge 1. Farklı sulama suyu tuzluluk seviyelerinde kök uzunluğu, fide kuru ağırlığı ve ortalama değerleri ve student's t çoklu karşılaştırma testi sonuçları

\begin{tabular}{|c|c|c|c|c|c|c|}
\hline \multirow{2}{*}{$\begin{array}{l}\text { Tuzluluk seviyesi }\left(\mathrm{dS} \mathrm{m}^{-1}\right) \\
\text { Kontrol }\end{array}$} & \multicolumn{2}{|c|}{ Kök uzunluğu (cm) } & \multicolumn{2}{|c|}{ Fide kuru ağırlığı (g) } & \multicolumn{2}{|c|}{ Çimlenme oranı (\%) } \\
\hline & 13.062 & a & 0.19357 & a & 100.00 & a \\
\hline 1 & 12.117 & $a b c$ & 0.19090 & $a$ & 95.24 & $a b$ \\
\hline 2 & 12.883 & $a b$ & 0.17803 & $a b$ & 95.24 & $a b$ \\
\hline 3 & 11.781 & $b c$ & 0.19801 & a & 90.48 & $a b c$ \\
\hline 4 & 11.292 & $\mathrm{~cd}$ & 0.17179 & $a b$ & 85.71 & abcd \\
\hline 5 & 10.467 & $d$ & 0.15418 & bc & 76.19 & cdef \\
\hline 6 & 8.620 & e & 0.14339 & $\mathrm{~cd}$ & 80.95 & bcde \\
\hline 7 & 8.043 & ef & 0.14220 & $\mathrm{~cd}$ & 71.43 & defg \\
\hline 8 & 7.342 & $\mathrm{fg}$ & 0.14150 & $\mathrm{~cd}$ & 71.43 & defg \\
\hline 9 & 7.185 & $\mathrm{fg}$ & 0.13029 & $\mathrm{~cd}$ & 61.90 & $\mathrm{fg}$ \\
\hline 10 & 6.590 & g & 0.12350 & $d$ & 66.67 & efg \\
\hline 12 & 6.768 & g & 0.12441 & $d$ & 61.90 & $\mathrm{fg}$ \\
\hline 16 & 5.250 & $\mathrm{~h}$ & 0.12493 & $d$ & 58.57 & g \\
\hline 20 & 4.183 & $h^{*}$ & 0.12204 & $d^{*}$ & 57.14 & g* \\
\hline
\end{tabular}

*: Aynı sütunda aynı harfle gösterilen ortalamalar arasındaki fark istatistiki açıdan önemsizdir $(\mathrm{P}<0.01)$.

Çizelge 2. Farklı sulama suyu tuzluluk seviyelerinde bitki boyu ve bitki kuru ağırlığı ortalama değerleri ve student's t çoklu karşılaştırma testi sonuçları

\begin{tabular}{llr}
\hline Tuzluluk seviyesi $\left(\mathbf{d S ~ ~ ^ { - 1 } )}\right.$ & Bitki boyu $(\mathbf{c m})$ & Bitki kuru ağırl \\
\hline 1 & $76.67 \mathrm{a}$ & $7.53 \mathrm{a}$ \\
3 & $74.00 \mathrm{ab}$ & $6.68 \mathrm{~b}$ \\
Kontrol & $70.67 \mathrm{bc}$ & $5.67 \mathrm{c}$ \\
5 & $67.00 \mathrm{c}$ & $4.12 \mathrm{c}$ \\
8 & $56.00 \mathrm{~d}$ & $2.63 \mathrm{~d}$ \\
12 & $50.33 \mathrm{e}$ & $1.97 \mathrm{f}$ \\
16 & $44.67 \mathrm{f}^{*}$ & $1.96 \mathrm{f}^{*}$
\end{tabular}

\footnotetext{
*: Aynı sütunda aynı harfle gösterilen ortalamalar arasındaki fark istatistiki açıdan önemsizdir $(\mathrm{P}<0.01)$.
} 


\section{Saksı Denemesi}

Yapılan varyans analizleri sonucunda saksı denemelerinde incelenen tüm özellikler açısından sulama suyu tuzluluk seviyelerinin etkileri istatistiki anlamda önemli bulunmuş olup $(P<0.01)$ ortalamalar student's t testi ile karşılaştırılmıştır.

Sulama suyu tuzluluk seviyesindeki artışa paralel

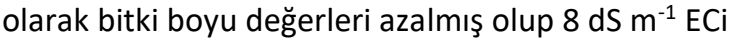
değerinde $(56.00 \mathrm{~cm})$ kontrolden $(70.67 \mathrm{~cm})$ farklı bir grup ortaya çıkmıştır. Sulama suyu tuzluluk seviyesindeki artışa paralel olarak bitki kuru ağırlığı değerleri azalmış olup $8 \mathrm{dS} \mathrm{m}^{-1}$ ECi değerinde (2.63 g) kontrolden $(5.67 \mathrm{~g})$ farklı bir grup ortaya çıkmıştır. Bitki boyu ve bitki kuru ağırlığı değerlerinin 1 ve $3 \mathrm{dS} \mathrm{m}^{-1} \mathrm{ECi}$ seviyelerinde kontrolden yüksek çıkmıştır (Çizelge 2).

\section{Toprak Tuzluluğu Analizleri}

Çalışma sonunda saksılardan alınan toprak örneklerinde Elektriksel İletkenlik (EC), pH, Ca, Mg, $\mathrm{Na}, \mathrm{K}, \mathrm{CO}_{3}, \mathrm{HCO}_{3}, \mathrm{Cl}$, ve $\mathrm{SO}_{4}$ analizleri yapılmıştır. Elde edilen sonuçlar ilgili başlıklar altında sunulmuştur. Çalışmada 0.5 [kontrol], 1, 3, 5, 8, 12 ve $16 \mathrm{dS} \mathrm{m}^{-1}$ iletkenliğe sahip sulama suları kullanılmıştır. Bitki kök bölgesindeki toprağın iyon değişimi sulama suyu tuzluluk seviyesine paralel olarak değişim göstermiştir. Artan sulama suyu tuz konsantrasyonuna bağlı olarak toprakta $\mathrm{Na}, \mathrm{Ca}$, $\mathrm{Mg}, \mathrm{Cl}$ ve $\mathrm{SO}_{4}$ miktarı da artış göstermiştir.

\section{Elektriksel iletkenlik Değerlerindeki Değişim}

Araştırma sonunda saksılardan alınan toprak örneklerinin Elektriksel illetkenlik (EC) değerleri, her sulama suyu tuzluluk konusuna bağlı olarak değişkenlik göstermiştir (Şekil 1). Toprak saturasyon ekstraktı EC'si en düşük olan konu kontrol konusu olmuştur. Artan sulama suyu tuzluluğuna paralel olarak toprakların tuz içeriği de artmış ve EC değerleri de buna bağlı olarak yükselmiştir. Kontrol konusunda toprak EC değeri

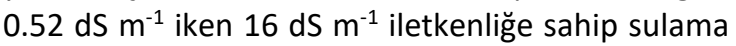
suyunun kullanıldığı konuda 17.54 dS $\mathrm{m}^{-1}$ ye ulaşılmıştır.

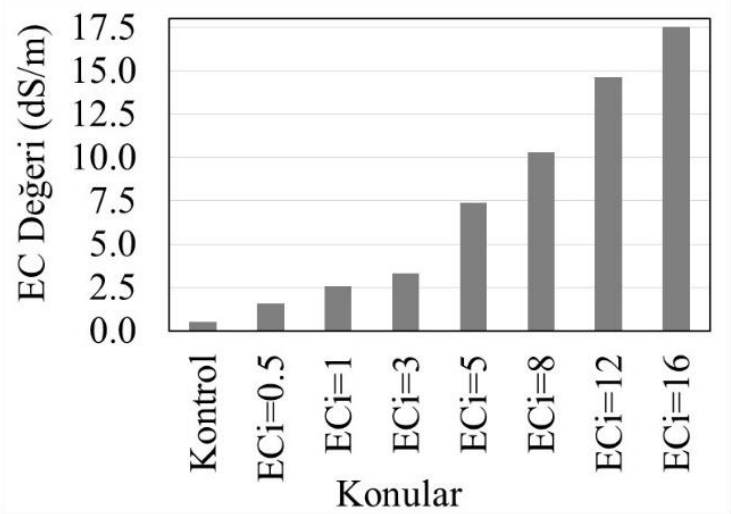

Şekil 1. Toprak Elektriksel İletkenlik Değerlerindeki Değişim

\section{Toprak pH'sındaki Değişim}

Araştırma sonunda saksılardan alınan toprak örneklerinin $\mathrm{pH}$ değerleri incelendiğinde genel olarak konular arasında farklılığın düşük olduğu görülmüştür (Şekil 2). En düşük toprak $\mathrm{pH}^{\prime}$ sı 7.24

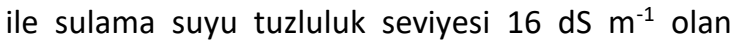
konularda ölçülürken, en yüksek değer kontrol konusunda 7.60 olarak ölçülmüştür.

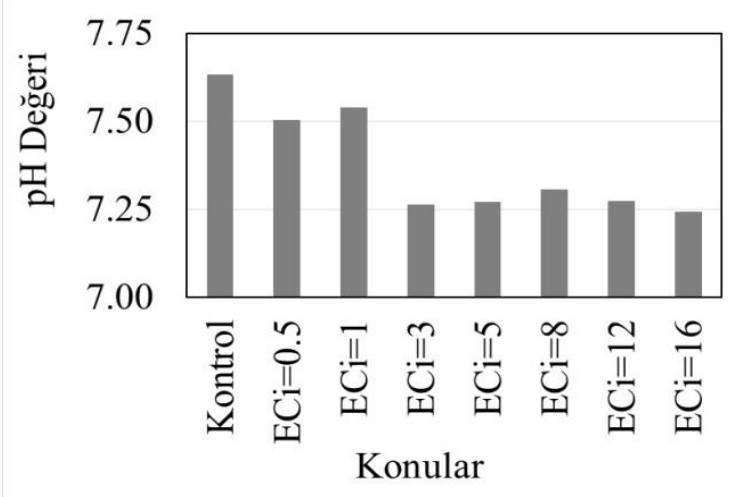

Şekil 2. Toprak pH Değerlerindeki Değişim

\section{Katyon Değerlerindeki Değişim}

Toprak örneklerinin $\mathrm{Na}, \mathrm{Ca} \mathrm{Mg}$ ve $\mathrm{K}$ iyonu içerikleri, konular arasında farklılık göstermiştir (Şekil 3). Bu farklılığın nedeni uygulanan sulama suyu tuz içeriğindeki farklılıktır. Artan tuz konsantrasyonu bağlı olarak sulama suyunun içerisinde, söz konusu iyonlarda artış göstermiştir. Sulama sularının hazırlanması sırasında SAR değerinin $1^{\prime}$ in altında olacak şekilde $\mathrm{NaCl}, \mathrm{CaCl}_{2}$ ve $\mathrm{MgSO}_{4}$ tuzları kullanılmıştır. Şekil 3'den de görüleceği üzere sulama suyu tuzluluğunun artmasına paralel olarak suların içinde çözünmüş $\mathrm{Na}, \mathrm{Ca}$ ve $\mathrm{Mg}$ iyonları da artmıştır. İyon içeriği bakımından en yüksek değerler, sulama suyu tuzluluğunun en yüksek olduğu konulardır. Ca değeri 3.44-16.69, Mg değeri 0.37-59.24, Na değeri 2.14-30.01 ve $\mathrm{K}$ değeri 0.06$0.26 \mathrm{me} \mathrm{L}^{-1}$ arasında değişim göstermiştir. $\mathrm{Na}, \mathrm{Ca}$ ve $\mathrm{Mg}$ iyon konsantrasyonu sulama suyu $\mathrm{ECi}$ artışına paralel olarak artarken $\mathrm{K}$ değeri de artış göstermiştir. Özellikle sulama suyu ECi'si $16 \mathrm{dS} \mathrm{m}^{-1}$ seviyesinde $\mathrm{K}$ konsantrasyonu artış göstermiştir. Bunun nedeni söz konusu uygulamada bitkilerin sulama suyu tuz stresine bağlı olarak gelişimi büyük oranda sınırlanması ve buna bağlı olarak verilen gübrenin bitkiler tarafından alınamamasıdır. Bu nedenle artan sulama suyu tuzluluğuna karşılık toprakta K içeriği de artış göstermiştir. 


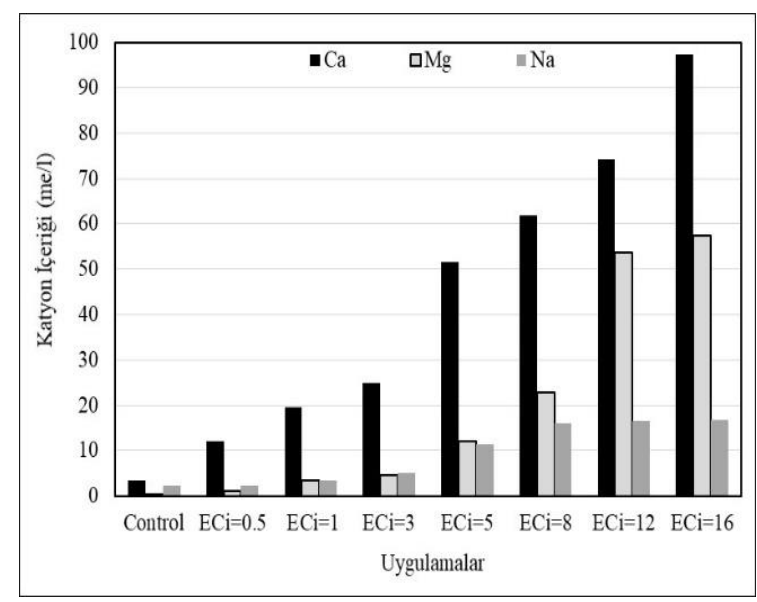

Şekil 3. Topraktaki Katyon Değişimi

\section{Anyon Değerlerindeki Değişim}

Anyonlardan bikarbonat $\left(\mathrm{HCO}_{3}\right)$, Klor $(\mathrm{Cl})$ ve sülfat $\left(\mathrm{SO}_{4}\right)$ değerlerinin konulara göre değişimi Şekil 4'de sunulmuştur. Şekilden de görüldüğü gibi artan tuz konsantrasyonuna bağlı olarak toprakta $\mathrm{Cl}$ ve $\mathrm{SO}_{4}$ artış göstermiştir. Söz konusu artışa nedeni sulama sularının hazırlanmasında kullanılan tuzlardan kaynaklanmaktadır. Sulama suyu tuzluluğunun yüksek olduğu konularda bitkiler söz konusu elementleri alamamış bu nedenle de kontrol konusuna göre söz konusu elementler yüksek miktarda toprakta birikmiştir. Torakta $\mathrm{HCO}_{3}$ değeri 1.47-2.90 değeri, $\mathrm{Cl}$ değeri 1.65-84.87 ve $\mathrm{SO}_{4}$ değeri 1.47-85.91 me $\mathrm{L}^{-1}$ arasında değişim göstermiştir.

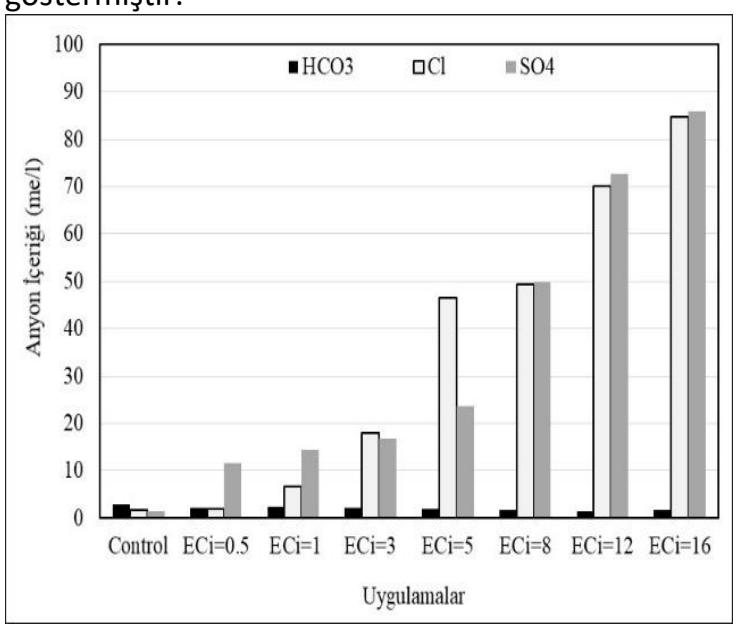

Şekil 4. Topraktaki Anyon Değişimi

\section{Değişebilir Sodyumdaki Değişim}

Sulama suyu olarak yüksek ECi'ye ve düşük SAR'a sahip sulama sularının kullanılması durumunda bitki kök bölgesindeki değişebilir iyon içeriği de değişim sergilemiştir (Şekil 5). Değişebilir sodyum iyonu bakımından en fazla değişim kontrol konusunda $2.24 \mathrm{me} \mathrm{L}^{-1}$ seviyesindeyken bu değer artan sulama suyu tuzluluğuna bağlı olarak azalma göstermiş ve en düşük değeri $12 \mathrm{dS} \mathrm{m}^{-1}$ iletkenliğe sahip sulama suyunun uygulandığı konuda 1.04 me/l seviyesine düşmüştür.

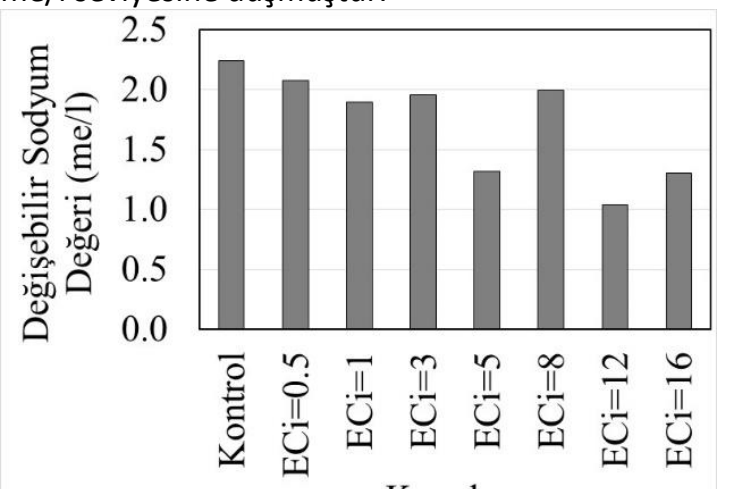

Konular

Şekil 5. Topraktaki Değişebilir Sodyum Değişimi

\section{Tartışma ve Sonuç}

Sulama suyu tuzluluk seviyesindeki artış ile birlikte çimlenme oranı değerleri azalmış olup $5 \mathrm{dS} \mathrm{m}^{-1} \mathrm{ECi}$ değerinde kontrolden farklı bir grup ortaya çıkmıştır. Bu durum için mısır tohumlarının çimlenmesi için ihtiyaç duyduğu suyun alımının sulama suyu tuzluluğunun $5 \mathrm{dS}$ $\mathrm{m}^{-1} \mathrm{ECi}$ seviyesinde ozmotik basıncın artışı ile azalmaya başlayarak çimlenmenin olumsuz etkilendiği söylenebilir. Duan ve ark. (2004), Chenopodium glaucum L. tohum çimlenmesine su stresi ve tuzluluğun etkilerini araştırdıkları çalışma sonucunda; tuzluluğun artmasıyla beraber ozmotik basınçtaki artış ile çimlenmenin oransal olarak önemli seviyede azaldığını beyan etmişlerdir. Sulama suyu tuzluluk seviyesindeki artışa paralel olarak mısır çim bitkisi kök uzunluğu değerleri azalmış olup, $3 \mathrm{dS} \mathrm{m}^{-1}$ seviyesinde kontrolden farklı bir grup ortaya çıkması mısır bitkisinin çim kökleri sulama suyu tuzluluğunun $3 \mathrm{dS} \mathrm{m}^{-1}$ seviyesinde tuza maruz kalmadan kaçınmak için gelişimini yavaşlatarak olumsuz etkilenmeye başlamış olabilir. Sulama suyu tuzluluk seviyesindeki artışa paralel olarak fide kuru ağırlığı değerleri de azalarak $5 \mathrm{dS} \mathrm{m}^{-1}$ değerinde kontrolden farklı bir grup ortaya çıkmıştır. Bu durum, mısır çim bitkisinin sulama suyu tuzluluğunun $5 \mathrm{dS} \quad \mathrm{m}^{-1}$ seviyesinde tuzluluğun etkisinden dolayı besin alımında sorun yaşamaya başladığı ve dolayısıyla olumsuz etkilenmeye başladığı şeklinde yorumlanabilir. Kara ve ark. (2011) farklı seviyelerdeki tuzluğun tritikalenin ( 6 genotip) çimlenme ve fide gelişimi üzerine etkilerini inceledikleri bir çalışmada; tüm genotiplerde tuzluluk seviyesi artışına paralel olarak zamana bağlı çimlenme oranı, fide boyu ve kök uzunluğunda kontrolle kıyaslandığında önemli azalışlar tespit ettiklerini bildirmişlerdir. Coşkun ve Taş (2017) farklı buğday türleri fide gelişimi üzerine sulama suyu tuzluluğunun 
etkilerini inceledikleri bir çalışmada; fide kök ve sürgününün $8 \mathrm{dS} \mathrm{m}^{-1}$ tuzluluk seviyesinde olumsuz etkilenmeye başladığını bildirmiştir. Akçaman ve ark. (2017) farklı sakız fasulyesi hatları ile yaptıkları bir çalışma sonucunda; sulama suyunun tuzluluk seviyesinin artışı ile beraber çimlenme hızı ve çimlenme gücünde azalma olduğunu belirtmişlerdir. Bagum ve ark. (2017) farklı hibrit mısır çeşitlerinin tuz toleranslarını belirlemek için yaptıkları bir çalışmada, tuz dozu artışının çimlenme oranı ve çimlenme hızında azalmalara sebep olduğunu ve çeşitlerin tuza toleransın farklı olduğunu bildirmektedir. Mısır tohumlarının çimlenme oranı, sürgün ve kök uzunlukları ile ağırlıkları artan tuzluluk ile önemli ölçüde azalmış olup bu etki genotiplere göre değişmiştir (Nuurismaan ve ark., 2018). Rysbekova ve ark. (2019) tuz dozu artışı ile kumdarı tohumlarının çimlenme oranında azamalar olduğunu bildirmektedirler.

Saksı denemesinde sulama suyu tuzluluk seviyesindeki artışa paralel olarak bitki boyu ve bitki kuru ağırlığı değerleri azalmış olup $8 \mathrm{dS} \mathrm{m}^{-1}$ değerinde kontrolden farklı gruplar ortaya çıkmıştır. Bu durum mısır bitkisinin sulama suyu tuzluluğunun $8 \mathrm{dS} \mathrm{m}^{-1}$ seviyesinde olumsuz etkilenmeye başladığı şeklinde yorumlanabilir.

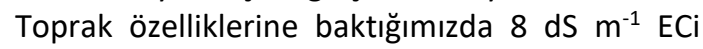
uygulamasına ait toprak EC değerinin $10 \mathrm{dS} \mathrm{\textrm {m } ^ { - }}$ ${ }^{1}$ nin üzerine çıktığı görülmektedir. Aslında bu durumda bitkinin maruz kaldığı toprak EC

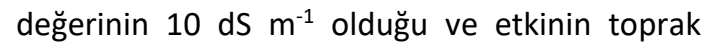
EC'sinin $10 \mathrm{dS} \mathrm{m}^{-1}$ olduğunda başladığı söylenebilir. Bitki boyu ve bitki kuru ağırlığı değerlerinin 1 ve $3 \mathrm{dS} \mathrm{m}^{-1} \mathrm{ECi}$ seviyelerinde kontrolden yüksek çıkması uygulanan tuzların içerdiği mineraller sebebiyle gübre etkisi yaptığı şeklinde yorumlanabilir. Chauhan ve Singh (1993), buğdayda 12 ve $16 \mathrm{dS} \mathrm{m}^{-1}$ tuzluluk düzeylerinde kuru madde miktarında \% 18 ve 33 , tane veriminde \% 21 ve 37 oranında azalma belirlediklerini bildirmişlerdir. Kara ve ark. (2011) farklı seviyelerdeki tuzluğun tritikalenin (6 genotip) çimlenme ve fide gelişimi üzerine etkilerini inceledikleri bir çalışmada; tüm genotiplerde tuzluluk seviyesi artışına paralel olarak fide boyu ve kök uzunluğunda kontrolle kıyaslandığında önemli azalışlar tespit ettiklerini bildirmişlerdir. Çelik ve Eraslan (2015) mısıra değişen dozlarda sodyum klorür ve nitrik oksit uyguladıkları bir çalışmada; uygulamalardaki doz artışıyla bitki yaş ve kuru ağırlığında kontrol ile kıyaslandığında ciddi miktarda azalmalar belirlemişlerdir. Arıcan ve Kale (2016) mısıra farklı düzeylerde tuzluluğa sahip sulama suları ve hidrojel uyguladıkları çalışma ile sulama suyunun tuzluluğu arttıkça bitki boyunun azaldığını belirlemişlerdir. Bagum ve ark. (2017) farklı hibrit mısır çeşitlerinde, tuz dozu artışının kök uzunluğu ve kuru ağırlık azalmasına ve çeşitlerin tuza toleransın farklı olduğunu bildirmektedir. Rysbekova ve ark. (2019) kumdarı bitkisi ile yaptıkları çalışmada kök ve sap uzunluğu ile biyomasın tuz dozu artışı ile azaldığını rapor etmiştir.

Toprak tuzluluğu analizleri sonucunda bitki kök bölgesinde, artan sulama suyu tuzluluğuna bağlı olarak $\mathrm{Ca}, \mathrm{Mg}$ ve $\mathrm{Na}$ iyonları başta olmak üzere iyon artışı belirlenmiştir. Belirli bir düzeye kadar toprak tamponlaması ve bitkinin kendi içsel mekanizmasıyla tolere edilebilir. Mısır bitkisinin çimlenme ve çıkış evresinde $5 \mathrm{dS} \mathrm{m}^{-1}$ sulama suyu tuzluluğuna kadar tolerans gösterebildiği ileriki dönemlerde ise $8 \mathrm{dS} \mathrm{m}^{-1}$ seviyesine kadar tolerans gösterdiği anlaşılmaktadır. François ve Mass. (1986), makarnalık ve ekmeklik buğdaylarla yürüttükleri bir saksı denemesinde bitkilerin ilk gelişim devrelerinde, ileriki gelişim devrelerine kıyasla, tuzluluk toleranslarının daha yüksek olduğunu bildirmektedirler. Yeterli miktarda temiz sulama suyunun olmadığı koşullarda az miktarda tuzlu su ilavesi yapılarak (bitkinin tolere edebileceği miktarda "5 dS m ${ }^{-1}$ 'ye kadar") mısır bitkisi yetiştirilebilir. Ancak bu durumda aşağıda belirtilen durumlara dikkat etmek gerekecektir:

Düşük SAR ile yüksek ECi değerlerine sahip olan sulama sularının kullanıldığı durumlarda, toprak geçirgenliği uygun olmalıdır. Bu özellikteki sulama sularının kullanılacağı topraklar, çok küçük değişim komplekslerine sahip olmalı ve mümkün olduğunca suyun kimyasal bileşiminden etkilenmemelidir. Sulama suyu ile birlikte yıkama suyu da uygulanmalı ve toprak permeabilitesi de kök bölgesindeki tuzun yıkanmasına olanak sağlayacak özelliklerde olmalıdır. Ayrıca, toprağın yapısı ve permeabilitesi sulama periyodu altında mevcut koşullarını koruyabilmelidir. Kullanılan suyun düşük SAR'a sahip olması ilk bakışta sorun oluşturmayabilir ancak uygun olmayan kültürel işlemler toprak iyon içeriğinde bozulmalara neden olabilir buna bağlı olarak da geçirgenlik azalır ve dolayısıyla da yıkamalar yetersiz kalır. Bunların sonucunda da sürdürülebilir toprak özelliklerinden uzaklaşılır. Sulama suyunun içerdiği tuzların türlerine bağlı olarak toprak minerallerinin özelliklerinde bir takım denge reaksiyonları oluşur ve toprak su çözeltisinin özellikleri değişir.

Toprakta fiziksel açıdan su-hava dengesinin sağlanması ve kümeli bir yapının olması arzu edilir. Toprakta oluşacak kümeli yapı, suyun hareketini kolaylaştırarak iyi bir su hava dengesinin oluşmasına yardımcı olur. Toprakta kümeli yapının oluşmasına etki eden faktörlerden bir tanesi de iki ve üç değerlikli katyonlardır. İki ve üç değerlikli 
katyonlar ve özellikle de Ca, kolloidal toprak tanelerinin gevşek formda kümeleşmesine neden olur. Bu biçimde kümeleşen toprak taneleri, organik atıkların etkisi ile daha dayanıklı bir hale dönüşür. Buna karşılık Na gibi tek değerlikli katyonlar iki ve üç değerlikli katyonların aksine toprakta teksel yapı oluşumuna neden olurlar.

Bitki kök bölgesinde başta $\mathrm{Ca}, \mathrm{Mg}$ ve $\mathrm{Na}$ olmak üzere tüm bitki besin elementleri dengeli bulunmak zorundadır. Örneğin bitki kök bölgesinin Ca bakımından zengin olması $\mathrm{P}, \mathrm{K}, \mathrm{Mg}, \mathrm{Zn}, \mathrm{Mn}$ ve $\mathrm{B}$ elementlerinin alınımını antagonistik etkileyerek sınırlandırmaktadır. Söz konusu bölgede tüm iyonların dengeli bulunması gerekmektedir. Toprak tuzluluk düzeyleri, uygulanan sulama suyu tuzluluklarına bağlı olarak artmıştır. Çalışmada elde edilen sonuçlar, Yurtseven ve ark. (2002), Özkay ve ark. (2014) ve Taş ve ark. (2017) ile uyum göstermektedir.

Ayer ve Westcot (1994), yüzey sulama yöntemlerinde klorun sorun olmayacak konsantrasyonu 4 meq $\mathrm{L}^{-1}$ ve hafif/orta şiddette sorun için 10 meq $\mathrm{L}^{-1}$ sınırını önermektedir. Yağmurla sulama yöntemlerinde sınır değeri 3 meq $\mathrm{L}^{-1}$ olarak belirtilmektedir. Bitki kök bölgesinde klorun fazla olması durumunda nitrat ile benzer iyonik özelliklerde olması nedeniyle bitkilerin nitrat alınımını olumsuz etkiler (Berges ve ark., 1995; Ashari ve Gholami, 2010; Taş ve ark., 2017).

Toprakta absorbe edilen sodyum değeri \%10-15'in üzerine çıktığında, kil matrisleri dağınık hale geçer, geçirgenlikleri azalır, toprak işleme zorlaşır, çimlenme sekteye uğrar ve dolayısıyla bitki gelişimi olumsuz yönde etkilenir (Kanber ve ark., 1992; Ekmekçi ve ark., 2005; Taş ve ark., 2017).

Sonuç olarak, sulama suyu SAR değeri 1'i geçmemek koşuluyla ECi değerinin $5 \mathrm{dS} \mathrm{m}^{-1}$ ye kadar mısır bitkisinin çimlenmesinde sorun oluşmamaktadır. Diğer bir ifadeyle, bu ECi değeri çimlenme ve çıkış evresi için eşik değeridir. Fide gelişimi dikkate alındığında mısır bitkisinin ECi değeri olarak $8 \mathrm{dS} \mathrm{m}^{-1}$ seviyesine kadar tolerans gösterdiği anlaşılmaktadır.

Teşekkür: Bu çalışma, Çanakkale Onsekiz Mart Üniversitesi Bilimsel Araştırma Projeleri Birimi tarafından desteklenen FBA-2018-1434 No'lu proje kapsamında yürütülmüş olup desteğinden dolayı çOMü Bilimsel Araştırma Projeleri Birimi'ne teşekkürlerimizi sunarız.

Çıkar Çatışması Beyanı: Makale yazarları aralarında herhangi bir çıkar çatışması olmadığını beyan ederler.
Araştırmacıların Katkı Oranı Beyan Özeti: Yazarlar makaleye eşit oranda katkı sağlamış olduklarını beyan ederler.

\section{Kaynaklar}

Akçaman, N., Taş, i.., Coşkun, Y., 2017. Farklı Sulama Suyu Tuzluluk Seviyelerinin Sakız Fasulyesi (Cyamopsis tetraganoloba)'nin Çimlenmesi Üzerine Etkileri. Türk Tarım ve Doğa Bilimleri Dergisi 4(2): 130-137

Arıcan, B. ve Kale, S., 2016. Farklı Sulama Suyu Tuzluluğu Koşullarında Değişik Hidrojel Dozlarının Şeker Mısır (Zea mays) Verimine Olan Etkileri. Süleyman Demirel Üniversitesi Ziraat Fakültesi Dergisi 11 (1):08-16

Ashari M.E., Gholami M., 2010. The effect of increased chloride (cl-) content in nutrient solution on yield and quality of strawberry (Fagaria ananassa Duch.) fruits. Journal of Fruit and Ornamental Plant Research Vol. 18(1) 2010: 37-44.

Ashraf, M. ve Foolad, M. R., 2007. Improving Plant Abiotic-Stress Resistance by Exogenous Application of Osmoprotectants Glycine Betaine and Proline. Environ. Exp. Bot. 59: 206-216.

Ayers, R.S. ve Westcot, D.W., 1994. Water Quality for Agriculture. FAO Irrigation of the Drainage Paper No:29. 163 s. Rome.

Bağcl, S.A., Ekiz H., Yılmaz, A., 2003. Determination of the Salt Tolerance of Some Barley Genotypes and the Characteristics Affecting Tolerance. Turk J Agric For. (27) 253-260.

Bagum, S., Billah, M., Hossain, N., Aktar, S. Uddin, S. 2017. Detection of salt tolerant hybrid maize as germination indices and seedling growth performance. Bulgarian Journal of Agricultural Science 23:793-798.

Berges J.A., Cochlan W.P., Harrison P.J. 1995. Laboratory and field responses of algal nitrate reductase to diel periodicity in irradiance, nitrate exhaustion, and the presence of ammonium. Mar. Ecol. Prog. Ser., pp. 124-128.

Chauhan, C. P. S. ve Singh, S. P., 1993. Wheat Cultivation Under Saline Irrigation. Wheat Information Service, 77: 33-38.

Coşkun, Y. ve Taş, I., 2017 Respons of Wheat Species to Irrigation Water Salinity. Genetika 49(2): 435 - 444.

Çelik, A. ve Eraslan, F. 2015. Nitrik Oksit Uygulamasının Tuz Stresi Altında Yetiştirilen Mısır Bitkisinin Mineral 
Beslenmesi ve Bazı Fizyolojik Özellikleri Üzerine Etkisi. Süleyman Demirel Üniversitesi Ziraat Fakültesi Dergisi 10 (1):55-64

Demir, I., Mavi, K., M., Okçu, G., 2003. Effect of Salt Stress on Germination and Seedling Growth in Serially Harvested Aubergine (Solanum melongena L.) Seeds During Development. Israel J. Plant Sci., 51: 125131.

Duan, D., Xiaojing, L., Ajmal Khan M. ve Bilquees, G., 2004. Effects of Salt and Water Stress on the Germination of Chenopodium glaucum L. seed. Pak. J. Bot., 36(4): 793800.

Ekmekçi, E., Apan, M., Kara, T., 2005. Tuzluluğun Bitki Gelişimine Etkisi. OMÜ Zir. Fak. Dergisi, 20(3):118-125.

Flowers, T. J., ve Yeo, A. R., 1981. Variability in the Resistance of Sodium Chloride Salinity Within Rice (Oryza sativa L.) Varieties. New Phytol, 88:363-373.

François, L.E., ve Mass, E.V., 1986. Effect of Salinity on Grain Yield and Quality, Vegetative Growth and Germination on Semi-Dwarf and Durum Wheat, Agros. J., 1053-1058.

İnal, A., Güneş, A., Aktaş, M., 1995. Effects of Chloride and Partial Substitution of Reduced Forms of Nitrogen for Nitrate in Nutrient Solution of the Nitrate, Total Nitrogen and Chlorine Contents of Onion. J Plant Nutrit, 18, 2219- 2227.

Kalefetoğlu, T. ve Ekmekçi, Y., 2005. The Effect of Drought on Plant and Tolerance Mechanisms, G.Ü. Fen Bilimleri Dergisi, Ankara, 18(4), 723-740.

Kanber R., Kırda C. Tekinel O., 1992. Sulama Suyu Niteliği ve Sulamada Tuzluluk Sorunları. Ç.Ü. Ziraat Fakültesi Genel Yayın No:21, Ders Kitapları Yayın No:6, Adana.

Kanber, R., ve Ünlü, M., 2010. Tarımda Su ve Toprak Tuzluluğu. Ç.Ü. Ziraat Fak. Gen. Yay. No:281. Ders Kitapları Yay. No:A-87 Adana. $307 \mathrm{~s}$

Kara, B., Akgün, İ., Altındal, D., 2011. Tritikale Genotiplerinde Çimlenme ve Fide Gelişimi Üzerine Tuzluluğun ( $\mathrm{NaCl}$ ) Etkisi. Selçuk Tarım ve Gıda Bilimleri Dergisi, 25 (1):1-9

Leopold, A.C. ve Willing, R.P., 1984. Evidence of Toxicity Effects of Salt on Membranes. Alınmıştır: Salinity Tolerance in Plants, (eds. R.C. Staples and G.H. Toenniessen), pp. 67-76.

Lewitt, J., 1980. Responses of Plants to Environmental Stresses. Vol.II, 2nd ed. Academic Press, New York, $607 \mathrm{~s}$.

Mansour, M.M.F., 1994. Changes in Growth,
Osmotic Potential and Cell Permeability of Wheat Cultivars Under Salt Stress. Biol Plant, 36: 429-434.

Nuurismaan, H., Hasan, Md., Shaddam, Md., Islam, M.S., Barutçular, C., EL Sabagh, A., 2018. Responses of Maize Varieties to Salt Stress in Relation to Germination and Seedling Growth. International Letters of Natural Sciences. 69. 10.18052/www.scipress.com/ILNS.69.1.

Özcan, S., Gürel, E., Babaoğlu, M., 2001. Bitki Biyoteknolojisi II. Selçuk Üniversitesi Yayınevi, Konya.

Özkay, F., Kıran, S., Taş, I.., Kuşvuran, Ş., 2014. Effects of Copper, Zinc, Lead and Cadmium Applied with Irrigation Water on Some Eggplant Plant Growth Parameters and Soil Properties. Türk Tarım ve Doğa Bilimleri Dergisi 1(3): 377-383, 2014

Rysbekova, A., Dyussibayeva, E., Zhirnova, I., Zhakenova, A., Seitkhozhayev, A., Makhmudova, C., Yancheva, S., Zhanbyrshina, N., Kipshakbayeva, G. 2019. Evaluation of salt tolerance of Panicum miliaceum $\mathrm{L}$. collection at the germination stage in conditions of induced sodium chloride salinization. Bulgarian Journal of Agricultural Science, 25(5): 986-993

Siegel, S. M., Siegel, B. Z., Massey, J., Lahne, P., Chen, J., 1980. Growth of Corn in Saline Water. Physiol Plant, 50: 71-73.

Taş, I., Coşkun, Y., Yeter, T., Yıldırım, Y.E., Görgişen, C., Özkay, F., 2017. Düşük SAR'a ve Yüksek Elektriksel Illetkenliğe Sahip Sulama Sularının Toprak İyon İçeriğine Etkisi. V. Uluslararası Katılımlı Toprak ve Su Kaynakları Kongresi. 12-15 Eylül, Kırklareli.

Van Hoorn, J.W., Katerjı, N., Hamdy, A., Mastrorilli, M., 2001. Effect of Salinity on Yield and Nitrogen Uptake of Four Grain Legumes and on Biological Nitrogen Contribution From the Soil. Agric Water Manag, 51, 8798.

Yurtseven, E., Çaycı, G., Sevimay, C.S., Öztürk, A., Parlak, M., Yalçın L., 2002. Tuzluluk ve su miktarlarının macar fiği (Vicia pannonica, Crantz) verimi ve toprak tuzluluğuna etkisi: I. yıkama uygulanmayan koşul. A.Ü. Ziraat Fak. Tarım Bilimleri Dergisi, 8(1):16, 2002. 